\title{
Impact of symptomatic hypoglycemia on medication adherence, patient satisfaction with treatment, and glycemic control in patients with type 2 diabetes
}

\author{
This article was published in the following Dove Press journal: \\ Patient Preference and Adherence \\ 30 April 2014 \\ Number of times this article has been viewed
}

\section{Lotta Walz',3 \\ Billie Pettersson ${ }^{2,3}$ \\ Ulf Rosenquist ${ }^{4}$ \\ Anna Deleskog 3,5 \\ Gunilla Journath ${ }^{6}$ \\ Per Wändell ${ }^{7}$}

'Department of Oncology-Pathology, Karolinska Institutet, Stockholm,

${ }^{2}$ Center for Medical Technology

Assessment, Linköping University, Linköping, ${ }^{3}$ Merck Sharp and

Dohme (Sweden) AB, Sollentuna,

${ }^{4}$ Department of Internal Medicine,

Motala Hospital, Motala, ${ }^{5}$ Department

of Molecular Medicine and Surgery,

${ }^{6}$ Department of Medicine, Karolinska Institutet, Stockholm, ${ }^{7}$ Department

of Neurobiology, Care Sciences and Society, Centre for Family Medicine, Karolinska Institutet, Huddinge, Sweden
Correspondence: Lotta Walz

Department of Oncology-Pathology, Karolinska Institutet, Campus Solna,

Stockholm, Sweden

Mobile +4670636 3323

Fax +468578I 3903

Email lotta.walz@ki.se
Background: The purpose of this study was to evaluate the impact of symptomatic hypoglycemia on medication adherence, satisfaction with treatment, and glycemic control in patients with type 2 diabetes based on the treatment goals stated in the Swedish national guidelines.

Methods: This cross-sectional, multicenter study was carried out between January and August 2009 in 430 consecutive primary health care patients on stable doses of metformin and sulfonylureas for at least 6 months. The patients completed questionnaires covering their experiences of low blood glucose and adherence, as well as barriers to and satisfaction with drug treatment (using the Treatment Satisfaction Questionnaire for Medication). Physicians collected the data from medical records.

Results: Patients who experienced moderate or worse symptoms of hypoglycemia reported poorer adherence to medication ( $46 \%$ versus $67 \% ; P<0.01)$ and were more likely to perceive barriers such as "bothered by medication side effects" ( $36 \%$ versus $14 \% ; P<0.001)$ compared with patients with no or mild symptoms. Patients with moderate or worse symptoms of hypoglycemia were less satisfied with their treatment than those with no or mild symptoms as determined by the Treatment Satisfaction Questionnaire for Medication-Global satisfaction (67.0 versus 71.2; $P<0.05)$. Overall, achievement of target glycated hemoglobin $\left(\mathrm{HbA}_{1 \mathrm{c}}\right)$ based on the treatment goals stated in the Swedish national guidelines was $40 \%$. Despite poorer adherence, patients who experienced moderate or worse symptoms of hypoglycemia had lower mean $\mathrm{HbA}_{1 \mathrm{c}}$ values than patients with no or mild symptoms (7.0\% versus $7.3 \%$ [Diabetes Control and Complications Trial standard]; $P<0.05$ ).

Conclusion: Symptomatic hypoglycemia in patients with type 2 diabetes on metformin and sulfonylureas was associated with nonadherence and decreased treatment satisfaction despite lower mean $\mathrm{HbA}_{1 \mathrm{c}}$ values. A broader understanding of patient preferences and self-reported outcomes could improve the management of patients with type 2 diabetes.

Keywords: hypoglycemia, patient-reported outcomes, primary care, nonadherence, persistence, sulfonylurea

\section{Introduction}

The incidence and prevalence of diabetes have increased worldwide. ${ }^{1}$ The prevalence in Sweden is about $4 \%-6 \%$, with the majority of patients $(85 \%-90 \%)$ being diagnosed with type 2 diabetes mellitus and mainly managed by general practitioners. ${ }^{2,3}$ The risk of serious cardiovascular complications is at least twice as high for patients with type 2 diabetes as in healthy controls. ${ }^{4,5}$ Multifactorial risk reduction and improved glycemic control based on current guidelines are central for these patients in order 
to delay or prevent complications and premature death. ${ }^{6-9}$ The beneficial effect of intensive glycemic control for minimizing microvascular complications is very strong in patients with type 2 diabetes. ${ }^{10}$ However, the relationship between intensive glycemic control and macrovascular outcomes is questionable given the recent studies suggesting that lowering glycated hemoglobin $\left(\mathrm{HbA}_{1 \mathrm{c}}\right)$ values below recommended levels $(<6 \%$ from the Diabetes Control and Complications Trial [DCCT]) increases the risk of hypoglycemia and does not lead to any further reduction in macrovascular events or all-cause mortality in these patients. ${ }^{10-13}$ However, both low and high mean $\mathrm{HbA}_{1 \mathrm{c}}$ values are associated with increased allcause mortality and macrovascular events. ${ }^{14}$ Adherence to the prescribed antihyperglycemic medication regimen has been found to be crucial for achieving and maintaining glycemic control and is associated with better clinical outcomes in patients with diabetes. ${ }^{15-18}$

To optimize treatment outcomes, Sweden has, like most other Western countries, formulated evidence-based guidelines and treatment goals. The Swedish goal for $\mathrm{HbA}_{1 \mathrm{c}}$ is $<6 \%$ (Swedish standard), which is comparable with the $<7 \%$ in the DCCT standard $(52 \mathrm{mmol} / \mathrm{mol}) .{ }^{19}$ Studies have confirmed that patients who achieve this goal have a reduced risk of cardiovascular events. ${ }^{20}$ However, despite treatment guidelines and good access to health care, less than half of patients with type 2 diabetes in Sweden achieve the recommended $\mathrm{HbA}_{1 \mathrm{c}}$ levels. ${ }^{21}$

Many antihyperglycemic therapies induce hypoglycemia, which is perceived as unpleasant by patients and can sometimes be life-threatening. ${ }^{22}$ Among the oral antihyperglycemic medications, sulfonylureas are particularly associated with an increased risk of hypoglycemia. ${ }^{23}$ The metformin and sulfonylurea regimen is recommended by Swedish national guidelines and is one of the antihyperglycemic combinations most frequently used in Sweden. ${ }^{19,21}$

It is challenging to achieve glycemic control in patients with type 2 diabetes without inducing hypoglycemia. Thus, it is important to identify and evaluate barriers to achieving and maintaining glycemic control in the type 2 diabetes population. To our knowledge, there are no studies that specifically focus on the symptoms of hypoglycemia and their impact on adherence, satisfaction with treatment, and goal attainment in patients with type 2 diabetes on metformin and sulfonylureas, which is one of the recommended oral treatment regimens in clinical practice in Sweden.

The aim of this study was to evaluate the impact of symptomatic hypoglycemia on medication adherence, treatment satisfaction, and glycemic control in patients with type 2 diabetes based on the treatment goals stated in the Swedish national guidelines.

\section{Patients and methods Patients and study design}

The study design has been published previously, ${ }^{24}$ and was essentially of a national, cross-sectional, and multicenter nature. Patients were on stable doses of metformin and sulfonylureas for at least 6 months prior to enrollment and were recruited consecutively from 54 locations in all of Sweden's 21 county councils by their general practitioners between January and August 2009 (Figure 1). The patients were asked to complete three questionnaires, ie, the Experiences of Hypoglycemia, Self-Reported Adherence and Barriers, and Treatment Satisfaction Questionnaire for Medication (TSQM). Primary care physicians completed a web-based case report form. ${ }^{24}$ The study protocol was approved in October 2008 by the Regional Ethical Review Board in Linköping (M185-08).

\section{Data collection}

Primary care physicians completed a web-based case report form with data collected from patient's health care records including age, sex, weight, height, diabetes duration, percent $\mathrm{HbA}_{1 \mathrm{c}}$ (expressed in Swedish mono standard; 6\% in Swedish mono standard corresponds to $7 \%$ in international standards [DCCT]), blood glucose, total cholesterol, highdensity lipoprotein cholesterol, triglycerides, blood pressure, other drug treatment, and history of macrovascular and microvascular events, as well as other major medical events. The patients had been on stable doses of metformin and sulfonylureas for at least 6 months prior to enrollment. The physicians also completed a questionnaire about changes in each patient's antihyperglycemic treatment during the visit. The patients completed a detailed eleven-item questionnaire comprising sociodemographic characteristics, ie, family history, educational level, marital status, and professional activity, and clinical characteristics, such as smoking habits, lifestyle, weight gain, and duration of diabetes.

\section{Experiences of hypoglycemia}

Patients were asked to complete the Experiences of Low Blood Sugar (Hypoglycemia) questionnaire used in earlier studies, comprising ten items on the frequency and severity of symptoms of hypoglycemia in the 6 months prior to the study. ${ }^{25}$ Mild symptoms were defined as causing "little or no interruption of activities, without need of assistance to manage symptoms," moderate symptoms were classified as 


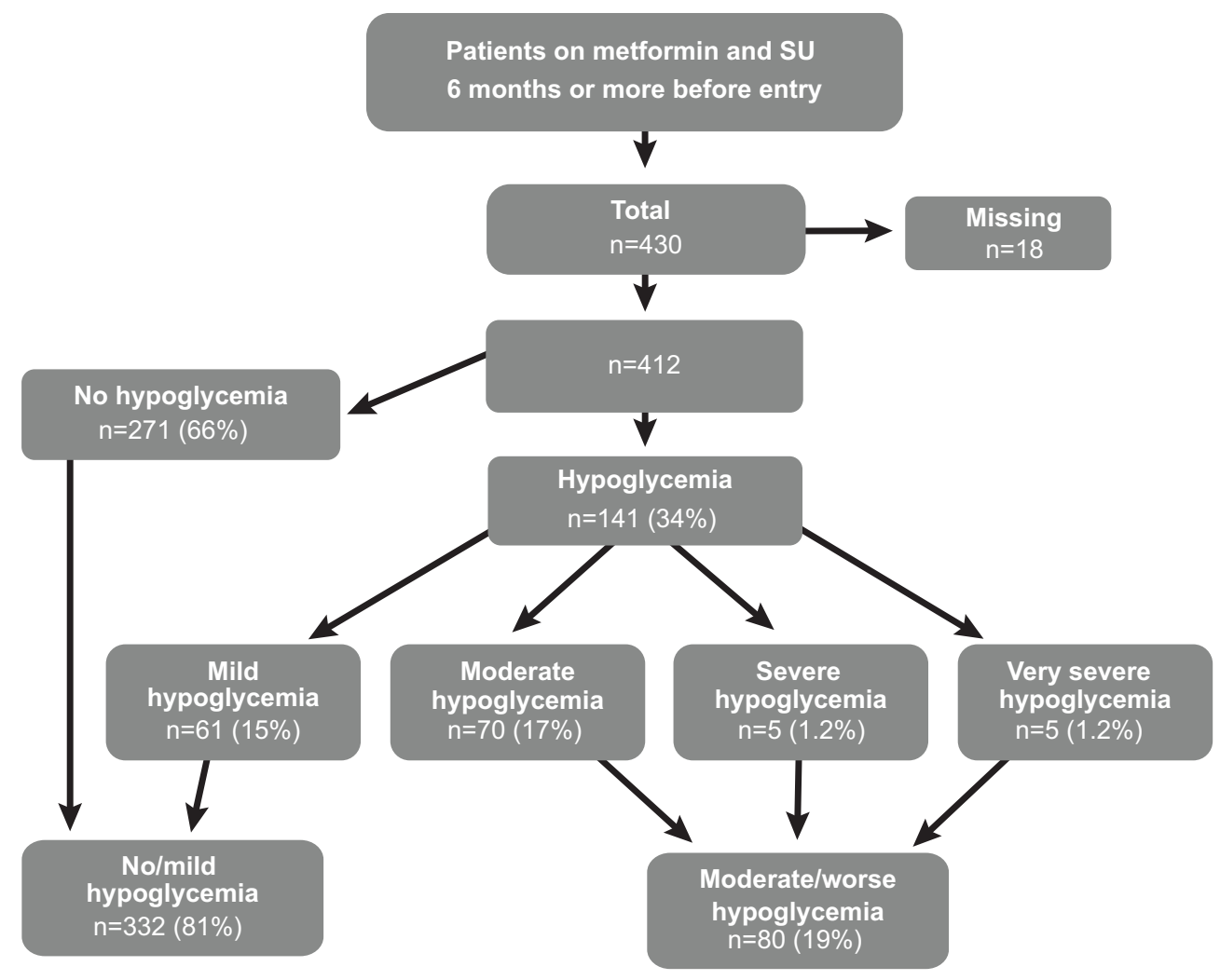

Figure I Study population.

Abbreviation: $\mathrm{SU}$, sulfonylureas.

"some interruption of activities, but without need of assistance to manage symptoms," severe symptoms were described as "interruption of activities with need of assistance from others to manage symptoms," and very severe symptoms were defined as "interruption of activities with need of medical attention." 24,25

Hypoglycemia symptoms were stratified by severity (none, mild, moderate, severe, or very severe). Group categorization was based on patient experiences of interruption of their activities due to symptoms of hypoglycemia, which is consistent with the definition used in a recent Cochrane review, where hypoglycemia was categorized as mild (controlled by patient), moderate (daily activities interrupted but self-managed), or severe (requiring assistance). ${ }^{13} \mathrm{We}$ dichotomized the group according to perceived interruption of activities; those who had no or mild symptoms of hypoglycemia (no activities interrupted) and those who had moderate or worse symptoms (activities interrupted), because there is evidence that quality of life is lower in patients with moderate or worse symptoms than among those with no or mild symptoms. ${ }^{24}$ Our hypothesis was that moderate and worse symptoms of hypoglycemia affect the patient's preferences and adherence in much the same way.

\section{Self-reported adherence and barriers}

A previously used self-report adherence and barriers questionnaire developed by Grant et al and also employed by others was used to assess adherence. ${ }^{26-28}$ This questionnaire contains 13 items; five are answered by "yes/no", five on a 5-point Likert scale, and three on an 8-point Likert scale. Six of the 13 questions concern smoking, diet, and physical activity (Table 1), while seven focus on adherence and barriers to medication adherence. The patients were clearly informed that the questions about adherence and barriers were intended to evaluate their experiences of antihyperglycemic treatment. To increase comparability, we decided to enter adherence as a dichotomous variable (always taking or not taking medications exactly as prescribed) and present the responses as in other studies using the same questionnaire. ${ }^{26-28}$ Adherence was estimated by three questions concerning the antihyperglycemic medication regimen: "How often do you take your diabetes medicines exactly as your health care provider prescribes them?"; "In the last week, how many days out of seven were you able to take all of your diabetes medicines?"; and "Did you take all of your diabetes medicines yesterday?". The rationale for using all three questions to classify patients as adherent or nonadherent (always taking or not taking 
Table I Patient characteristics and study groups of no/mild symptoms versus moderate/worse symptoms of hypoglycemia and groups of adherent versus nonadherent patients. Data are expressed as the mean and standard deviation for continuous variables and as a percentage for categorical variables

\begin{tabular}{|c|c|c|c|c|c|c|c|}
\hline & $\begin{array}{l}\text { Total } \\
(n=430)\end{array}$ & $\begin{array}{l}\text { No/mild } \\
(n=332)\end{array}$ & $\begin{array}{l}\text { Moderate/worse } \\
(n=80)\end{array}$ & $P$-value & $\begin{array}{l}\text { Adherent } \\
(n=260)\end{array}$ & $\begin{array}{l}\text { Nonadherent } \\
(n=\mid 43)\end{array}$ & $P$-value \\
\hline Age (years) & $69.0(9.5)$ & $69.8(9.1)$ & $64.6(9.9)$ & $0.00 I^{*}$ & $70.3(9.5)$ & $66.3(8.9)$ & $0.00 I^{*}$ \\
\hline BMI $\left(\mathrm{kg} / \mathrm{m}^{2}\right)$ & $28.7(4.3)$ & $28.8(4.4)$ & $28.5(4.1)$ & 0.23 & $28.8(4.4)$ & $28.6(4.3)$ & 0.30 \\
\hline $\mathrm{HbA}_{\mathrm{IC}}(\mathrm{mmol} / \mathrm{L})$ latest value ${ }^{\dagger}$ & $7.2(1.0)$ & $7.3(0.8)$ & $7.0(0.8)$ & $0.03 *$ & $7.2(1.0)$ & $7.2(\mathrm{I} . \mathrm{I})$ & 0.62 \\
\hline Fasting blood glucose $(\mathrm{mmol} / \mathrm{L})$ & $8.4(2.2)$ & $8.5(2.3)$ & $7.9(2.0)$ & 0.08 & $8.3(2.0)$ & $8.5(2.4)$ & 0.35 \\
\hline Total cholesterol $(\mathrm{mmol} / \mathrm{L})$ & $4.6(0.9)$ & $4.6(0.9)$ & $4.5(0.9)$ & 0.47 & $4.5(0.9)$ & $4.6(0.9)$ & 0.27 \\
\hline Cholesterol LDL (mmol/L) & $2.6(0.8)$ & $2.6(0.8)$ & $2.6(0.7)$ & 0.64 & $2.6(0.8)$ & $2.6(0.8)$ & 0.61 \\
\hline Triglycerides (mmol/L) & $\mathrm{I} .8(0.8)$ & $1.8(0.9)$ & I.7 (0.8) & 0.21 & I.7 (0.8) & $1.8(0.9)$ & 0.33 \\
\hline Cholesterol HDL (mmol/L) & I.2(0.4) & I.2(0.4) & I.2(0.3) & 0.53 & I.2(0.4) & I.2(0.4) & 0.87 \\
\hline Systolic BP (mmHg) & I37.I (I5.8) & I37.8 (I6.3) & I34.4 (I4.6) & 0.30 & I37.9 (I5.8) & I35.4 (16.0) & 0.37 \\
\hline Diastolic BP (mmHg) & $76.3(9.1)$ & $76.6(8.9)$ & $75.5(9.7)$ & 0.04 & $76.6(9.3)$ & $75.8(8.7)$ & 0.06 \\
\hline Tablets/day (n) & $4.8(1.4)$ & $4.7(1.4)$ & $4.8(1.5)$ & 0.75 & $4.8(1.4)$ & $4.7(1.3)$ & 0.55 \\
\hline Gender: male & 60.7 & 60.2 & 62.5 & 0.85 & 56.2 & 69.3 & 0.07 \\
\hline Diabetes duration $>7$ years & 71.0 & 70.8 & 70.9 & 0.51 & 71.9 & 70.0 & 0.83 \\
\hline History of microvascular event & 18.8 & 19.9 & 14.5 & 0.50 & 17.9 & 21.5 & 0.28 \\
\hline History of macrovascular event & 32.6 & 32.4 & 33.3 & 0.32 & 36.5 & 27.1 & 0.50 \\
\hline Goal attained $\left(\mathrm{HbA}_{\mathrm{IC}}\right)^{\mathrm{a}}$ & 40.4 & 38.6 & 48.1 & 0.14 & 38.2 & 42.0 & 0.49 \\
\hline Married & 12.4 & 13.3 & 8.9 & 0.23 & 12.4 & 11.8 & 0.63 \\
\hline Higher education & 14.3 & 12.5 & 21.5 & 0.12 & 12.9 & 17.2 & 0.49 \\
\hline Physical activity & 75.9 & 74.9 & 80.0 & 0.53 & 77.7 & 71.7 & 0.16 \\
\hline Smoking & 12.1 & 12.3 & 11.2 & 0.64 & 10.0 & 15.0 & 0.47 \\
\hline No change in treatment & 85.2 & 84.9 & 86.2 & 0.86 & 87.3 & 81.7 & 0.15 \\
\hline Adherent & 67.0 & 67.1 & 46.2 & $0.0 I^{*}$ & & & \\
\hline Nonadherent & 37.0 & 32.9 & 53.8 & $0.01 *$ & & & \\
\hline Moderate/worse hypoglycemia & & & & & 14.5 & 28.7 & $0.003^{*}$ \\
\hline
\end{tabular}

Notes: ${ }^{\dagger 7.0 \% ~ D C C T ~ s t a n d a r d ~}(52 \mathrm{mmol} / \mathrm{mol})$; ${ }^{\text {a }} \mathrm{HbA}_{\mathrm{lc}}$ goal according to Swedish national guidelines; missing patients are excluded; $P$-values age-adjusted. $* P<0.05$.

Abbreviations: BP, blood pressure; BMI, body mass index; LDL, low-density lipoprotein cholesterol; HDL, high-density lipoprotein cholesterol; HbA $\mathrm{A}_{I C}$, hemoglobin $\mathrm{A}_{\mathrm{IC}}$; DCCT, Diabetes Control and Complications Trial.

medications exactly as prescribed) was to minimize the risk of overestimating adherence.

\section{Treatment Satisfaction Questionnaire for Medication}

Patient satisfaction with oral antihyperglycemic medication was analyzed using the TSQM version 1.4 . The TSQM is a validated questionnaire containing 14 items. ${ }^{29}$ The dimensions measured are side effects (five items), effectiveness (three items), convenience (three items), and global satisfaction (three items). Items are answered by "yes/no" or on a 5-point or 7-point Likert scale. A score per dimension was calculated ranging from 0 to 100 , with a higher score indicating greater satisfaction with treatment.

\section{Data analysis}

Standard descriptive statistical methods were used to summarize patient demographics and responses. The Student's $t$-test was applied when comparing groups of continuous variables. Analysis of variance was used when more than two groups were compared. All analyses were adjusted for differences in age, and the age-adjusted $P$-values were calculated by means of analysis of covariance for continuous variables and the Cochran Mantel-Haenszel test for categorical variables. The Mann-Whitney $U$ test was applied when the $t$-test requirements were not met and the Kruskal-Wallis test when more than two groups were compared. Categorical data were presented in percentages. Chi-squared tests were used for the questionnaires and group affiliation. All tests were two-sided and statistical significance was considered to be established at a $P$-value of less than 0.05 . The test of independence was used to identify the association between several variables in cross tables. The null hypothesis was classified as independent, ie, Pearson's Chi-squared $P$-values of less than 0.05 imply that there is dependence between variables. All analyses were performed using Statistical Package for the Social Sciences versions 19 and 20 software (IBM Corporation, Armonk, NY, USA).

\section{Results \\ Patients}

Of 430 patients with type 2 diabetes included, nearly one fifth (19\%) described moderate or more severe symptoms 
of hypoglycemia in the 6 months prior to the study, during which they were treated with metformin in combination with sulfonylureas. The mean age of the study population was 69 years, and $61 \%$ of subjects were men. The group with no or mild hypoglycemia symptoms was older than the group with moderate or worse symptoms of hypoglycemia (70 years versus 65 years; $P<0.001$ ). After age adjustment, no gender differences were observed between the hypoglycemia severity groups or between the adherent and nonadherent groups. All patients were on stable doses of metformin and sulfonylureas; the mean daily dose of metformin was $1.9 \mathrm{mg}$ and the mean daily sulfonylurea dose was $4.8 \mathrm{mg}$ of glibenclamide and $2.1 \mathrm{mg}$ of glimepiride or $7.1 \mathrm{mg}$ of glipizide. The most frequently used sulfonylurea was glibenclamide (64\%). No significant difference in mean doses or type of sulfonylurea was observed between the hypoglycemia severity groups or between the adherent and nonadherent groups. The baseline data and sociodemographics are summarized in Table 1.

\section{Experiences of hypoglycemia}

Nearly one third of the patients experienced some form of hypoglycemic symptoms (Figure 1). Patients were dichotomized into groups classified as no or mild (81\%) and moderate or worse $(19 \%)$ experiences of hypoglycemia.

\section{Self-reported adherence and barriers}

Thirty-seven percent of all patients were classified as nonadherent, ie, they reported that they did not adhere to agreed antihyperglycemic treatment instructions (Table 1). Patients with moderate or worse symptoms of hypoglycemia reported poorer adherence $(46 \%$ versus $67 \% ; P<0.01)$ compared with

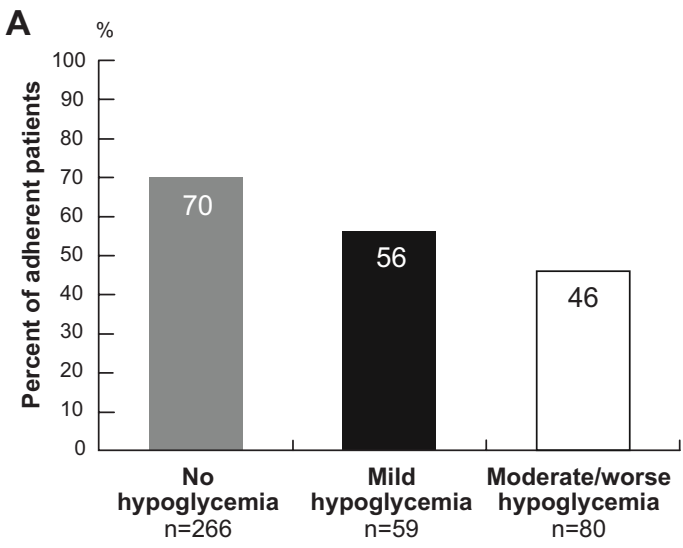

patients with no or mild symptoms. Adherence was negatively associated with severity of symptoms of hypoglycemia and more likely in patients who did not experience such symptoms (Figure 2). Patients with moderate or worse symptoms of hypoglycemia were more likely to report barriers to adherence than patients with no or mild symptoms (Figure 3 ). Table 1 shows that there were no sociodemographic differences such as marital status or educational level and no divergence in clinical characteristics between the severity groups or between the adherent and nonadherent groups.

\section{Satisfaction with treatment}

Patients with moderate or worse symptoms of hypoglycemia had lower scores on the scales for satisfaction with effectiveness (67.7 versus $70.3 ; P<0.05$ ), satisfaction with side effects (87.1 versus $94.4 ; P<0.001)$, and global satisfaction (67.0 versus $71.2 ; P<0.05$ ) compared with patients reporting no or mild symptoms (Table 2 ).

\section{Mean $\mathrm{HbA}_{\mathrm{Ic}}$ and glycemic control}

The mean $\mathrm{HbA}_{1 \mathrm{c}}$ in the study population was 7.2\% DCCT standard (55 mmol/mol). Mean $\mathrm{HbA}_{1 \mathrm{c}}$ was lower in the group of patients with moderate or worse symptoms of hypoglycemia versus the group with no or mild symptoms (7.0\% versus $7.3 \%$ DCCT standard; $P<0.05)$. The mean $\mathrm{HbA}_{1 \mathrm{c}}$ did not differ between groups when stratified by duration of diagnosed diabetes or between the adherent and nonadherent groups. Overall achievement of target $\mathrm{HbA}_{1 \mathrm{c}}$ based on the treatment goals stated in the Swedish national guidelines was only $40 \%$. The test of independence revealed that achievement of target $\mathrm{HbA}_{1 \mathrm{c}}$ was significantly associated with the severity of symptoms of hypoglycemia (Figure 2).

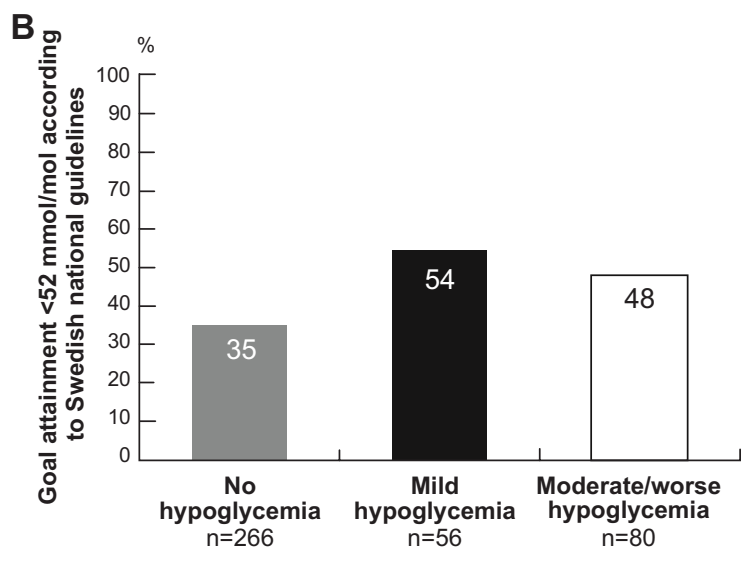

Figure 2 (A) Proportion of patients who reported adherence with antihyperglycemic medication in relation to severity of symptoms of hypoglycemia. Test of independence, Pearson's chi-squared test $P<0.005$. (B) Proportion of patients with glycated hemoglobin goal attainment based on national guidelines in relation to severity of symptoms of hypoglycemia. Test of independence, Pearson's chi-squared test, $P<0.005$. Missing patients were excluded. 


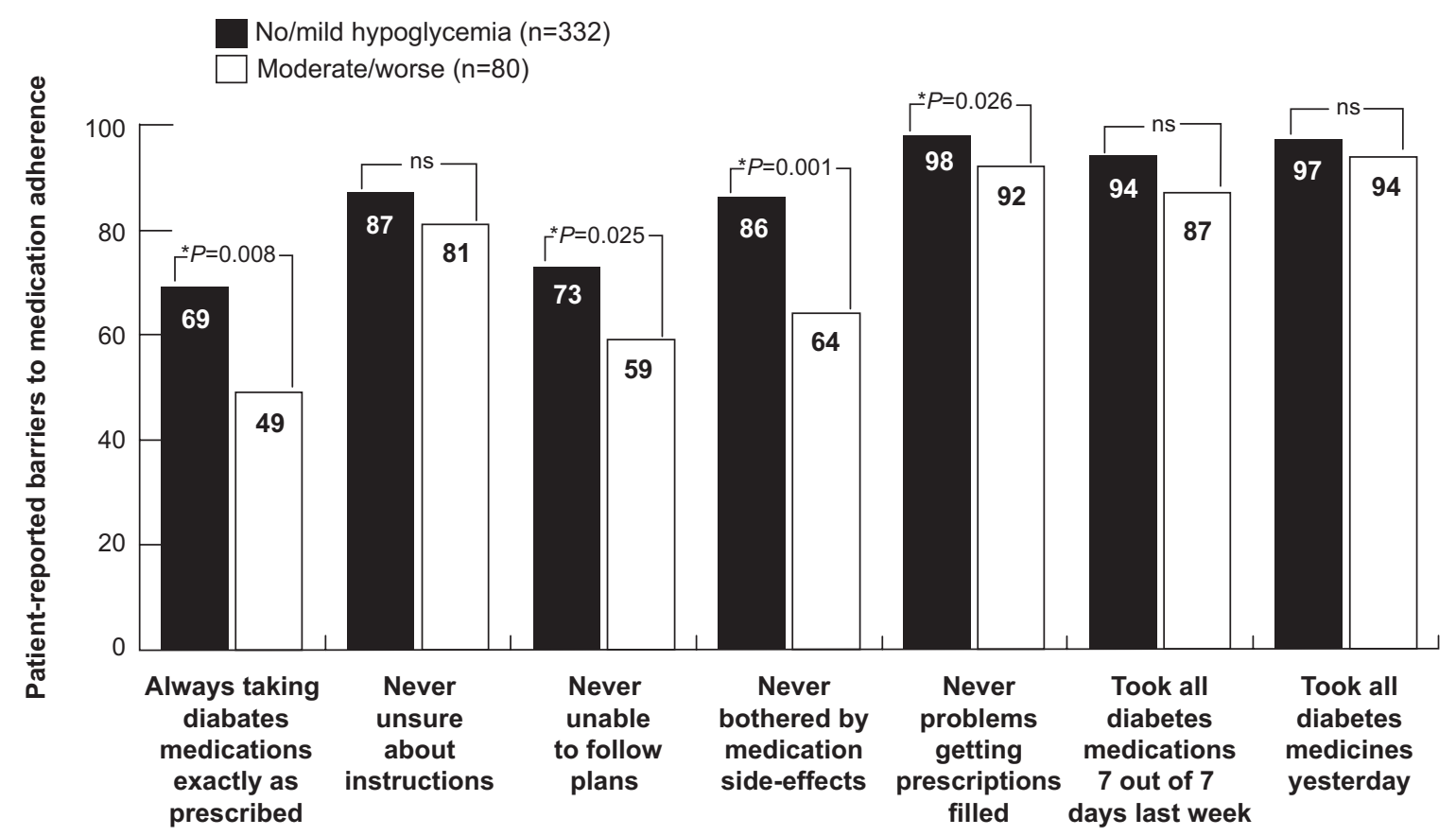

Figure 3 Overall scores of reported adherence and barriers to adherence (\%) in the study groups with no/mild symptoms and moderate/worse symptoms of hypoglycemia. $P$-values are age-adjusted. $* P<0.05$.

\section{Discussion}

The main finding in our study was that symptomatic hypoglycemia, classified as moderate or worse, was associated with nonadherence in patients with type 2 diabetes treated with the recommended antihyperglycemic drug combination of metformin and sulfonylureas. Overall nonadherence was $37 \%$, which is consistent with the findings of other studies. ${ }^{22,23,25}$ However, in patients with moderate or worse symptoms of hypoglycemia, more than half (54\%) reported nonadherence, which is twice as high as the average nonadherence rate $(24.8 \%)$ in a quantitative review of adherence research. ${ }^{30}$

Studies conducted in Europe have analyzed the association between hypoglycemia and management of type 2 diabetes, and our results confirm that patients walk a thin line between glycemic control and symptoms of hypoglycemia. ${ }^{24,26,31-35}$ Hypoglycemia is associated with lower quality of life, poorer adherence, and higher risk of discontinuation of antihyperglycemic treatment, and can complicate the overall treatment outcome in patients with type 2 diabetes. ${ }^{17,24,31,36,37}$ There is evidence that poor adherence to medication and lack of persistence with treatment in patients diagnosed with a chronic disease, including type 2 diabetes, have an adverse impact on public health and overall mortality, as well as contributing substantially to increased health care costs. ${ }^{38-42}$ Our results suggest that glycemic control is achieved at the expense of symptoms of hypoglycemia in patients with type 2 diabetes treated with metformin and sulfonylureas.

The RECAP-DM (Real-Life Effectiveness and Care Patterns of Diabetes Management) study, conducted in seven European countries, indicated that patients with type 2 diabetes who experienced symptoms of hypoglycemia reported more barriers to medication adherence than

Table 2 Treatment Satisfaction Questionnaire for Medication scores for all patients as well as categories of no/mild and moderate/ worse hypoglycemia

\begin{tabular}{|c|c|c|c|c|}
\hline TSQM dimension & $\begin{array}{l}\text { All patients } \\
(n=430)\end{array}$ & $\begin{array}{l}\text { No/mild } \\
(n=332)\end{array}$ & $\begin{array}{l}\text { Moderate/worse } \\
(n=80)\end{array}$ & P-value \\
\hline Effectiveness (0-100) & $69.7 \pm 10.9$ & $70.3 \pm 10.8$ & $67.7 \pm 11.2$ & $0.029 *$ \\
\hline Side effects $(0-100)$ & $92.9 \pm 16.2$ & $94.4 \pm 14.0$ & $87.1 \pm 21.8$ & $0.000 I^{*}$ \\
\hline Convenience $(0-100)$ & $75.1 \pm 12.0$ & $75.6 \pm 12.1$ & $73.9 \pm 11.6$ & 0.081 \\
\hline Global satisfaction $(0-100)$ & $70.3 \pm 16.1$ & $71.2 \pm 16.2$ & $67.0 \pm 16.0$ & $0.036 *$ \\
\hline
\end{tabular}

Notes: $P$-values are age-adjusted; missing patients are excluded; data are expressed as the mean and standard deviation. $* P<0.05$.

Abbreviation: TSQM, Treatment Satisfaction Questionnaire for Medication. 
patients who experienced no symptoms. ${ }^{26}$ These findings are supported by our study. However, patients in RECAP-DM were dichotomized by no or any form of hypoglycemia. When dichotomizing our population in an analogous way, we also found poorer adherence in the group with any form of symptomatic hypoglycemia compared with patients who had no symptoms $(50 \%$ versus $70 \%, P<0.002)$.

In RECAP-DM, reaching target $\mathrm{HbA}_{1 \mathrm{c}}$ status was associated with adherence to medication. It is worth noting that, in our study, symptomatic patients showed better goal status despite poorer adherence than the group with no symptoms $(51 \%$ versus $35 \% ; P<0.002)$. However, Table 1 shows that there were no differences in glycemic control between the adherent and nonadherent groups in our study, which was unexpected.

An interesting explanation proposed by others may be that good adherence to medication will only have an impact on glycemic control if suitable doses and an effective antihyperglycemic regimen are prescribed. ${ }^{43,44}$ It has been found that suboptimal treatment seems to be more common than nonadherence to antihyperglycemic medication among patients with type 2 or uncontrolled diabetes. ${ }^{45}$ Concern about hypoglycemia and awareness of the negative consequences for quality of life prevents both patients and physicians from adhering to the treatment instructions. ${ }^{46,47}$ Our patients had been on the study treatment satisfaction for at least 6 months and had various perspectives on their symptoms of hypoglycemia, nonadherence, and treatment. Patient records indicated poor overall glycemic control. Nevertheless, in $85 \%$ of cases, the primary care physicians did not change the antihyperglycemic treatment at the study visit.

Patient-reported outcomes are reports provided directly by the patients themselves about how they function or feel in relation to a health condition and its therapy, and are therefore not interpreted by a clinician or anyone else. ${ }^{48}$ The purpose of patient-reported outcomes is to provide the patient perspective, which might help health care professionals to assess the effectiveness of treatment, understand symptoms and other outcomes, and recognize disease progression. ${ }^{49,50}$ When assessing the effectiveness of a treatment regimen in the clinical setting, it is important to consider patient-reported outcomes in order to establish whether uncontrolled diabetes is due to poor adherence with the prescribed antihyperglycemic treatment regimen or if poor glycemic control is caused by inadequate antihyperglycemic treatment. In chronic diseases such as type 2 diabetes, the patient perspective on functioning and well-being is essential, given that the main objectives of treatment are to avoid or delay complications and to maintain or improve quality of life. ${ }^{49}$ Our results highlight the need for a broader understanding of patient preferences and patient-reported outcomes to improve the management of type 2 diabetes.

Patients with moderate or worse symptoms of hypoglycemia indicated several dimensions where they were less satisfied with their antihyperglycemic medication regimen than patients with no or mild symptoms, which is consistent with previous findings for patients with type 2 diabetes. ${ }^{26}$ Patients who experienced moderate or worse symptoms of hypoglycemia reported lower global satisfaction in the TSQM survey and were less satisfied with the effectiveness of their antiglycemic medications and side effects, despite having lower $\mathrm{HbA}_{1 \mathrm{c}}$ values. Decreased treatment satisfaction should be taken seriously because it is associated with poorer adherence and an increased risk of discontinuation and nonpersistence. ${ }^{51}$ Inadequate persistence has been identified as one of the leading adherence problems in patients with a chronic disease, including type 2 diabetes. ${ }^{31}$

The main strength of this study is that its participants constituted a representative population of patients in Swedish primary health care. It was conducted in a primary care setting and 430 patients with type 2 diabetes treated with one of the recommended combination regimens were consecutively enrolled. Patients were recruited during a regular visit to their general practitioner at 54 locations in all of Sweden's 21 county councils. We consider the homogeneity of the sociodemographic variables to be a strength of this study when analyzing the impact of symptomatic hypoglycemia on medication adherence, treatment satisfaction, and glycemic control (Table 1).

Symptomatic hypoglycemia was one of the key observations in this study, but there is no consensus on the definition of hypoglycemia in the literature, which may limit the generalizability of our results. ${ }^{52}$ However, our categorization of hypoglycemic symptoms is consistent with the definition of hypoglycemic episodes in a recent Cochrane review. ${ }^{13}$ It is most likely that symptoms of hypoglycemia were related to sulfonylureas with no or limited influence of metformin..$^{23}$ The questionnaires in this study have been previously used to identify and categorize symptoms of hypoglycemia, and yielded consistent results. ${ }^{25}$ However, in our study, patient-reported symptomatic hypoglycemia relied on patients' memory, which may favor more severe symptoms and thus might have affected the proportions in the two severity groups. Another possible limitation is that the patients had been on the study treatment for at least 6 months prior to enrollment. Those who experienced more severe symptomatic hypoglycemia or any other adverse 
side effect were most likely taken off treatment and only those who tolerated the study medication were enrolled. This could have led to an underestimation of the frequency and consequences of moderate and worse symptoms of hypoglycemia. Our results indicate that, when treating patients with type 2 diabetes using a combination of metformin and sulfonylureas in clinical practice, experiences of symptomatic hypoglycemia could be even more prevalent than was the case in this study. Patients with no and mild symptoms were older than those who reported moderate and worse symptoms. Given that awareness of the warning signs of hypoglycemia is impaired in the elderly, it is possible that older patients had just as many moderate or worse symptoms of hypoglycemia as younger patients, but were not aware of them. However, in our study, we evaluated the patients' experiences of symptoms of hypoglycemia and the impact of such symptoms on adherence and goal attainment. Asymptomatic hypoglycemia is not considered to change patient behavior. Symptomatic hypoglycemia occurred more often in patients with lower $\mathrm{HbA}_{1 \mathrm{c}}$ values. These results indicate the reliability of self-reports because lower $\mathrm{HbA}_{1 \mathrm{c}}$ is associated with an increased risk of hypoglycemia. Blood glucose levels were not measured at the time of the hypoglycemic symptoms. Thus, any correlation between the severity of symptoms of hypoglycemia and actual blood glucose levels was not possible. However, the results may be clinically relevant due to the significant association between the participants' perception of symptoms of hypoglycemia and nonadherence to medication.

No single method for measuring adherence described in the literature has proven to be completely adequate. ${ }^{53}$ The variety of methods and lack of a definition of adherence limit the ability to compare our results with other studies. However, the literature suggests that self-reported questionnaires provide an adequate estimate of adherence, ${ }^{54}$ and our results rely on a well-known and previously used questionnaire. ${ }^{26-28}$

\section{Conclusion}

We conclude that experiences of symptomatic hypoglycemia in patients with type 2 diabetes treated with metformin and sulfonylureas are associated with nonadherence, barriers to adherence, and decreased patient satisfaction with treatment despite better glycemic control. Given that the objective of glycemic control is to prevent or delay complications and maintain quality of life, our results highlight the importance of a broader understanding of patient-reported outcomes to improve the management of type 2 diabetes.

\section{Disclosure}

The authors report no conflicts of interest in this work.

\section{References}

1. Wild S, Roglic G, Green A, Sicree R, King H. Global prevalence of diabetes estimates for the year 2000 and projections for 2030. Diabetes Care. 2004;27(5):1047-1053.

2. Carlsson AC, Wandell P, Osby U, Zarrinkoub R, Wettermark B, Ljunggren G. High prevalence of diagnosis of diabetes, depression, anxiety, hypertension, asthma and COPD in the total population of Stockholm, Sweden - a challenge for public health. BMC Public Health. 2013; 13(1):670.

3. Wirehn AB, Karlsson HM, Carstensen JM. Estimating disease prevalence using a population-based administrative healthcare database. Scand J Public Health. 2007;35(4):424-431.

4. Huxley R, Barzi F, Woodward M. Excess risk of fatal coronary heart disease associated with diabetes in men and women: meta-analysis of 37 prospective cohort studies. BMJ. 2006;332(7533):73-78.

5. Stamler J, Vaccaro O, Neaton JD, Wentworth D. Diabetes, other risk factors, and 12-yr cardiovascular mortality for men screened in the Multiple Risk Factor Intervention Trial. Diabetes Care. 1993;16(2):434-444.

6. Gaede P, Lund-Andersen H, Parving HH, Pedersen O. Effect of a multifactorial intervention on mortality in type 2 diabetes. $N$ Engl J Med. 2008;358(6):580-591.

7. Ray KK, Seshasai SR, Wijesuriya S, et al. Effect of intensive control of glucose on cardiovascular outcomes and death in patients with diabetes mellitus: a meta-analysis of randomised controlled trials. Lancet. 2009;373(9677):1765-1772.

8. Stratton I, Cull C, Adler A, Matthews D, Neil H, Holman R. Additive effects of glycaemia and blood pressure exposure on risk of complications in type 2 diabetes: a prospective observational study (UKPDS 75). Diabetologia. 2006;49(8):1761-1769.

9. Turnbull FM, Abraira C, Anderson RJ, et al. Intensive glucose control and macrovascular outcomes in type 2 diabetes. Diabetologia. 2009;52(11):2288-2298.

10. Skyler JS, Bergenstal R, Bonow RO, et al. Intensive glycemic control and the prevention of cardiovascular events: implications of the ACCORD, ADVANCE, and VA diabetes trials: a position statement of the American Diabetes Association and a scientific statement of the American College of Cardiology Foundation and the American Heart Association. Diabetes Care. 2009;32(1):187-192.

11. Duckworth W, Abraira C, Moritz T, et al. Glucose control and vascular complications in veterans with type 2 diabetes. $N$ Engl J Med. 2009;360(2):129-139.

12. Gerstein HC, Miller ME, Byington RP, et al. Effects of intensive glucose lowering in type 2 diabetes. $N$ Engl J Med. 2008;358(24):2545-2559.

13. Hemmingsen B, Lund SS, Gluud C, et al. Intensive glycaemic control for patients with type 2 diabetes: systematic review with meta-analysis and trial sequential analysis of randomised clinical trials. $B M J$. 2011;343:d6898.

14. Currie CJ, Peters JR, Tynan A, et al. Survival as a function of $\mathrm{HbA}_{1 \mathrm{c}}$ in people with type 2 diabetes: a retrospective cohort study. Lancet. 2010;375(9713):481-489.

15. Asche C, LaFleur J, Conner C. A review of diabetes treatment adherence and the association with clinical and economic outcomes. Clin Ther. 2011;33(1):74-109.

16. Guillausseau PJ. Influence of oral antidiabetic drugs compliance on metabolic control in type 2 diabetes. A survey in general practice. Diabetes Metab. 2003;29(1):79-81.

17. Pladevall M, Williams LK, Potts LA, Divine G, Xi H, Lafata JE. Clinical outcomes and adherence to medications measured by claims data in patients with diabetes. Diabetes Care. 2004;27(12):2800-2805.

18. Rhee MK, Slocum W, Ziemer DC, et al. Patient adherence improves glycemic control. Diabetes Educ. 2005;31(2):240-250.

19. The Swedish National Board of Health and Welfare. National Guidelines for Diabetes Care, 2010. Available from: http://www.socialstyrelsen. se/nationellariktlinjerfordiabetesvarden. Accessed February 5, 2013. 
20. Eeg-Olofsson K, Cederholm J, Nilsson PM, et al. New aspects of $\mathrm{HbA}_{1 \mathrm{c}}$ as a risk factor for cardiovascular diseases in type 2 diabetes: an observational study from the Swedish National Diabetes Register (NDR). J Intern Med. 2010;268(5):471-482.

21. Ekstrom N, Miftaraj M, Svensson AM, et al. Glucose-lowering treatment and clinical results in 163,121 patients with type 2 diabetes: an observational study from the Swedish National Diabetes Register. Diabetes Obes Metab. 2012;14(8):717-726.

22. Burge MR, Sood V, Sobhy TA, Rassam AG, Schade DS. Sulphonylureainduced hypoglycaemia in type 2 diabetes mellitus: a review. Diabetes Obes Metab. 1999;1(4):199-206.

23. Belsey J, Krishnarajah G. Glycaemic control and adverse events in patients with type 2 diabetes treated with metformin + sulphonylurea: a meta-analysis. Diabetes Obes Metab. 2008;10 Suppl 1:1-7.

24. Pettersson B, Rosenqvist U, Deleskog A, Journath G, Wandell P. Self-reported experience of hypoglycemia among adults with type 2 diabetes mellitus (Exhype). Diabetes Res Clin Pract. 2011;92(1):19-25.

25. Vexiau P, Mavros P, Krishnarajah G, Lyu R, Yin D. Hypoglycaemia in patients with type 2 diabetes treated with a combination of metformin and sulphonylurea therapy in France. Diabetes Obes Metab. 2008;10 Suppl 1:16-24.

26. Alvarez Guisasola F, Tofe Povedano S, Krishnarajah G, Lyu R, Mavros P, Yin D. Hypoglycaemic symptoms, treatment satisfaction, adherence and their associations with glycaemic goal in patients with type 2 diabetes mellitus: findings from the Real-Life Effectiveness and Care Patterns of Diabetes Management (RECAP-DM) Study. Diabetes Obes Metab. 2008;10 Suppl 1:25-32.

27. Grant RW, Devita NG, Singer DE, Meigs JB. Improving adherence and reducing medication discrepancies in patients with diabetes. Ann Pharmacother. 2003;37(7-8):962-969.

28. Grant RW, Devita NG, Singer DE, Meigs JB. Polypharmacy and medication adherence in patients with type 2 diabetes. Diabetes Care. 2003;26(5):1408-1412.

29. Atkinson MJ, Sinha A, Hass SL, et al. Validation of a general measure of treatment satisfaction, the Treatment Satisfaction Questionnaire for Medication (TSQM), using a national panel study of chronic disease. Health Qual Life Outcomes. 2004;2:12.

30. DiMatteo MR. Variations in patients' adherence to medical recommendations: a quantitative review of 50 years of research. Med Care. 2004;42(3):200-209.

31. Bron M, Marynchenko M, Yang H, Yu AP, Wu EQ. Hypoglycemia, treatment discontinuation, and costs in patients with type 2 diabetes mellitus on oral antidiabetic drugs. Postgrad Med. 2012;124(1):124-132.

32. Cryer PE. Hypoglycemia: still the limiting factor in the glycemic management of diabetes. Endocr Pract. 2008;14(6):750-756.

33. Davis S, Alonso MD. Hypoglycemia as a barrier to glycemic control. J Diabetes Complications. 2004;18(1):60-68.

34. Levit S, Toledano Y, Wainstein J. Improved glycaemic control with reduced hypoglycaemic episodes and without weight gain using longterm modern premixed insulins in type 2 diabetes. Int J Clin Pract. 2011;65(2):165-171.

35. Nyhlin KT, Lithner F, Norberg A. Experience of being diabetic. Scand J Caring Sci. 1987;1(2):59-67.

36. Alazri MH, Neal RD. The association between satisfaction with services provided in primary care and outcomes in type 2 diabetes mellitus. Diabet Med. 2003;20(6):486-490.
37. Davis RE, Morrissey M, Peters JR, Wittrup-Jensen K, KennedyMartin T, Currie CJ. Impact of hypoglycaemia on quality of life and productivity in type 1 and type 2 diabetes. Curr Med Res Opin. 2005;21(9):1477-1483.

38. Cramer JA. A systematic review of adherence with medications for diabetes. Diabetes Care. 2004;27(5):1218-1224.

39. Ho PM, Rumsfeld JS, Masoudi FA, et al. Effect of medication nonadherence on hospitalization and mortality among patients with diabetes mellitus. Arch Intern Med. 2006;166(17):1836-1841.

40. Sokol MC, McGuigan KA, Verbrugge RR, Epstein RS. Impact of medication adherence on hospitalization risk and healthcare cost. Med Care. 2005;43(6):521-530.

41. White TJ, Vanderplas A, Chang E, Dezii CM, Abrams GD. The costs of nonadherence to oral antihyperglycemic medication in individuals with diabetes mellitus and concomitant diabetes mellitus and cardiovascular disease in a managed care environment. Disease Management and Health Outcomes. 2004;12(3):181-188.

42. Wild $H$. The economic rationale for adherence in the treatment of type 2 diabetes mellitus. Am J Manag Care. 2012;18(3 Suppl):S43-S48.

43. Glasgow RE, Toobert DJ, Riddle M, Donnelly J, Mitchell DL, Calder D. Diabetes-specific social learning variables and self-care behaviors among persons with type II diabetes. Health Psychol. 1989;8(3):285-303.

44. Johnson SB. Methodological issues in diabetes research. Measuring adherence. Diabetes Care. 1992;15(11):1658-1667.

45. Schmittdiel JA, Uratsu CS, Karter AJ, et al. Why don't diabetes patients achieve recommended risk factor targets? Poor adherence versus lack of treatment intensification. J Gen Intern Med. 2008;23(5):588-594.

46. Cryer PE. Hypoglycemia is the limiting factor in the management of diabetes. Diabetes Metab Res Rev. 1999;15(1):42-46.

47. Lundkvist J, Berne C, Bolinder B, Jonsson L. The economic and quality of life impact of hypoglycemia. Eur J Health Econ. 2005;6(3): 197-202.

48. Patrick DL, Burke LB, Powers JH, et al. Patient-reported outcomes to support medical product labeling claims: FDA perspective. Value Health. 2007;10:S125-S137.

49. Revicki D, Hays RD, Cella D, Sloan J. Recommended methods for determining responsiveness and minimally important differences for patient-reported outcomes. J Clin Epidemiol. 2008;61(2):102-109.

50. Willke RJ, Burke LB, Erickson P. Measuring treatment impact: a review of patient-reported outcomes and other efficacy endpoints in approved product labels. Control Clin Trials. 2004;25(6):535-552.

51. Barrett-Connor E, Wade SW, Do TP, et al. Treatment satisfaction and persistence among postmenopausal women on osteoporosis medications: 12-month results from POSSIBLE US. Osteoporos Int. 2012;23(2):733-741.

52. Amiel SA, Dixon T, Mann R, Jameson K. Hypoglycaemia in type 2 diabetes. Diabet Med. 2008;25(3):245-254.

53. Cramer JA, Mattson RH, Prevey ML, Scheyer RD, Ouellette VL. How often is medication taken as prescribed? A novel assessment technique. JAMA. 1989;261(22):3273-3277.

54. Garber MC, Nau DP, Erickson SR, Aikens JE, Lawrence JB. The concordance of self-report with other measures of medication adherence: a summary of the literature. Med Care. 2004;42(7):649-652.
Patient Preference and Adherence

\section{Publish your work in this journal}

Patient Preference and Adherence is an international, peer-reviewed, open access journal that focusing on the growing importance of patient preference and adherence throughout the therapeutic continuum. Patient satisfaction, acceptability, quality of life, compliance, persistence and their role in developing new therapeutic modalities and compounds to optimize

\section{Dovepress}

clinical outcomes for existing disease states are major areas of interest for the journal. This journal has been accepted for indexing on PubMed Central. The manuscript management system is completely online and includes a very quick and fair peer-review system, which is all easy to use. Visit http://www. dovepress.com/testimonials.php to read real quotes from published authors. 